\title{
Assessment of the Storm Avoidance Effect on the Wave Climate along the Main North Atlantic Routes
}

\author{
Roberto Vettor and C. Guedes Soares \\ (Centre for Marine Technology and Ocean Engineering (CENTEC) \\ Instituto Superior Técnico, Universidade de Lisboa, Portugal) \\ (E-mail: c.guedes.soares@centec.tecnico.ulisboa.pt)
}

\begin{abstract}
The wave climate along the main transoceanic routes of the North Atlantic sub basin is determined using three different databases: two derived by numerical models in the HIPOCAS and ERA40 databases and one from Voluntary Observing Ships. For each route the distribution of the mean significant wave height along the path is computed as well as the specific scatter diagram. In addition an assessment of the relative wave heading probability is provided. The results highlight a bias in the visual observations especially in the summer and, more in general, for low sea states. The correction of this bias allows better understanding of rough weather avoidance by ships and to determine a storm avoidance correction.
\end{abstract}
KEYWORDS
1. Ship routes.
2. North Atlantic.
3. Weather routing.
4. Storm avoidance.

Submitted: 28 November 2014. Accepted: 29 May 2015. First published online: 24 June 2015.

1. INTRODUCTION. An accurate and reliable description of the weather that a ship will experience in its life is essential, not only for design purposes, but also for fleet management, to schedule mantainance and to provide recomendations to the master and the route planner.

Recently several global wave climate studies, using wave hindcasts or reanalysis, have been published (Uppala et al., 2005; Chawla et al., 2012; Stopa et al., 2013; Fan et al., 2012). Also some long-term regional wave climate studies using downscaled wave hindcasts were pursued (e.g., Weisse and Günther, 2007; Pilar et al., 2008; Lionello and Galati, 2008). This attempt to investigate sea waves in more detail is not only impelled by scientific interest. Wind waves have a significant impact on offshore and coastal infrastructures, ship design and routing, beach erosion and sediment transport, for example, and are an important element in extreme events, like storm surges and flooding in coastal areas.

In ship design the North Atlantic weather is widely used as a reference for the establishment of the reference values of extreme wave induced loads in ships and it is the one adopted by the International Association of Classification Societies (IACS) to 
establish the design conditions for ships. The attempts to use different wave databases to determine the most probable wave loads a ship will be subjected to, show a significant scatter in the predictions (Guedes Soares and Viana, 1988; Guedes Soares and Trovão, 1991; 1992; Bitner-Gregersen and Guedes Soares, 2007), and also shows differences from the values along different routes (Guedes Soares and Moan, 1991; Queirós et al., 2012). However the use of the various databases normally leads to higher values than prescribed in the design rules and the explanation is that ships tend to avoid the roughest weather and thus are exposed to somewhat lower sea states. However, the effect of storm avoidance has not yet been fully quantified and this paper makes a step in that direction.

Besides the importance of the IACS recommendations, especially to take into account the extreme events that a ship can be asked to withstand maybe a few times in its life, it is useful to represent the actual environment that ships usually experience in their voyages across the Atlantic. While in the design phase a conservative approach is still recommended, when the schedule of a ship during the year or of an entire fleet has to be planned by assessing operability, knowledge of what conditions can be expected along the actual routes would significantly improve the results. This becomes particularly relevant in the present conditions in which energy efficiency, fuel consumption and emissions are being more considered as a priority (Papanikolaou et al., 2014; Prpic-Oršic et al., 2015).

As was shown in a previous work (Vettor and Guedes Soares, 2015), for geographic and economic reasons, most of the trades in the North Atlantic are carried out along a few specific tracks, so it is there that more effort has been made to provide voluntary observations of weather conditions.

Sophisticated systems are nowadays used on board to choose the route that fulfils the targets, and onshore to provide recommendations to avoid dangerous conditions. This allows ships to avoid some rough weather, an aspect that is inherently contained in the Visual Observing Ships (VOS) wave data. Ships, in fact, provide reports only relative to the location and moment in which they are passing. Consequently, if ships tend to avoid storms, which means avoiding high Significant Wave Heights (SWHs), the VOS database will not contain those events, or at least they will be in a lower percentage than they actually occur in climatological databases. This paper attempts to quantify this effect along the abovementioned North Atlantic routes.

Section 2 describes the main North Atlantic routes. In Section 3 an overview of the three wave databases used in this study is given. In Section 4 the different climate, dependent on the covered route is described with an attempt to provide all useful elements to adopt as an input for ship performance and response analysis. In this perspective, besides the average significant wave height, also the scatter diagram and the relative wave heading probability are presented. In Section 5 a discussion on the bias encountered in the VOS data and a simple correction is applied, highlighting the effect of storm avoidance on statistics from VOS reports. The concept of storm avoidance correction is introduced in Section 6 and an equation for its estimation is proposed. Conclusions and final remarks are made in Section 7.

2. MAIN NORTH ATLANTIC ROUTES. In Vettor and Guedes Soares (2015) the tracks of the main North Atlantic routes were identified from the VOS database 


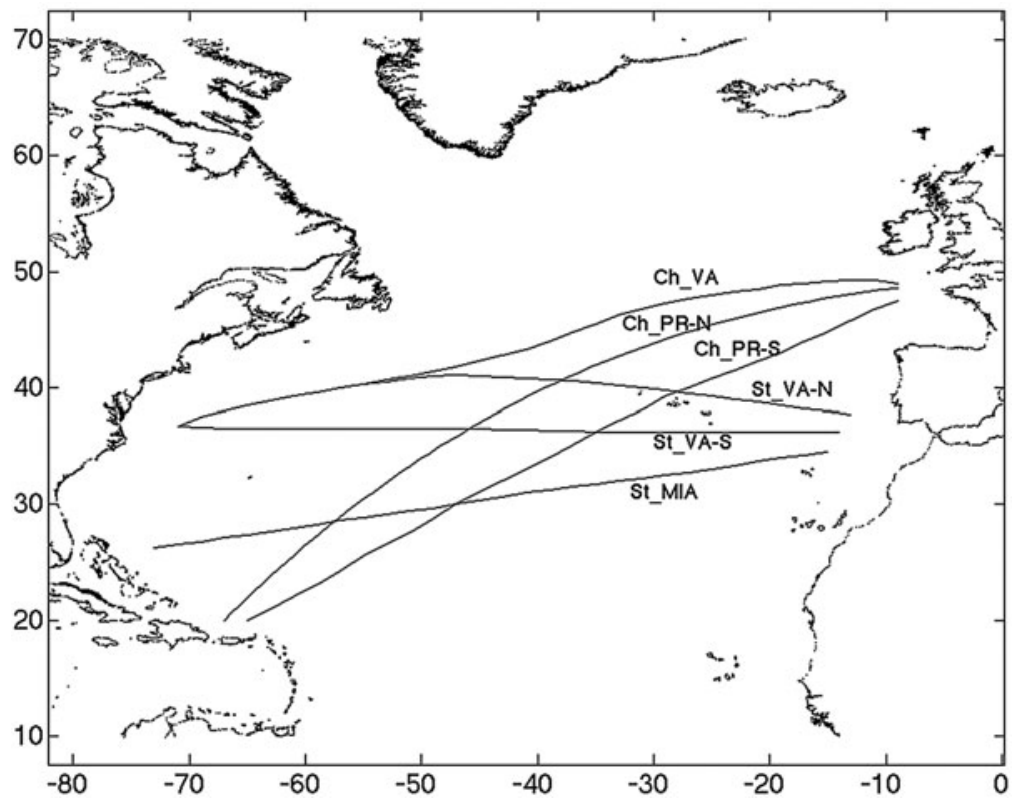

Figure 1. Main North Atlantic trans-oceanic routes.

following the area with a higher density of reports and with some consideration of global economy and geography.

Six main trans-oceanic passages were detected as follows and depicted in Figure 1:

- Route 1: Channel - Puerto Rico (North), [Ch_PR-N]

- Route 2: Channel - Puerto Rico (South), [Ch_PR-S]

- Route 3: Channel - Virginia, [Ch_VA]

- Route 4: Strait - Virginia (North), [St_VA-N]

- Route 5: Strait - Virginia (South), [St_VA-S]

- Route 6: Strait - Miami, [St_MIA]

It was shown that the most used stream is the one from Northern Europe (the Channel) to the Caribbean Sea (Ch_PR-N and Ch_PR-S) with 36\% of the traffic in the considered areas (higher percentages in winter). More than one-third of these ships prefer the northern and shorter orthodrome.

The routes between the Strait of Gibraltar and the North-East Coast of USA (St_VA-N and St_VA-S) denote a similar concentration with about $32 \%$ of the trades, while the routes from the Channel to the Virginia area (Ch_VA) and from Gibraltar to Miami (St_MIA) contribute 21\% and 10\% respectively.

Rough weather avoidance was found to influence the choice of the routes and it is mainly highlighted on the northern passages, which are always less frequented in winter. Overall, May is the month with the highest presence of ships, whereas in December it reduces by almost $20 \%$.

3. WAVE DATABASES. A wave database contains climatological data in a spatial grid covering a specific area, which can be obtained from simulation models, 
measurements or observations. Modern phase averaging third generation wave models (Komen et al., 1994; WISE Group, 2007) predict the spatial and temporal evolution of the directional spectrum solving the spectral energy equation.

Numerical models as well as data assimilation schemes have gone through various improvements in recent decades causing variability in the long-term data not related to natural variability. The reanalysis aim is to overcome the inhomogeneities related to the model (Sterl and Caires, 2005): the best available model is used to repeat the analysis procedure throughout the period in consideration. Inhomogeneities related to the changes in data coverage remain.

Two numerical databases, namely HIPOCAS (Hindcast of Dynamic Processes of the Ocean and Coastal Areas of Europe) and ERA40 (ECMWF Re-analysis-40), and the International Comprehensive Ocean-Atmosphere Data Set (ICOADS) archive containing the voluntary observations have been used and compared in this work.

The first hindcast database derives from the EU project HIPOCAS (Guedes Soares, 2008) aimed at producing a 44 year database of wave, wind and sea level for all seas around Europe with a $2^{\circ} \times 2^{\circ}$ resolution. In addition a data set from the whole North Atlantic was also produced in order to determine the swell conditions that would be arriving on the Atlantic coasts of Europe (Pilar et al., 2008). The initial wind field was from the NCEP reanalysis (Kalnay et al., 1996), which was used to force a regional atmospheric model REMO (Jacob and Podzun, 1997; von Storch et al., 2000), which finally forced the WAM wave model (WAMDI, 1988). The data was validated with buoy measurements establishing its general adequacy (Pilar et al., 2008). A comparison with the database from the National Oceanic and Atmospheric Administration (NOAA) showed the general consistency between these two databases (Campos and Guedes Soares, 2012).

The WAM model is also the base of the European Centre for Medium-Range Weather Forecast (ECMWF) atmospheric ERA-40 reanalysis (Uppala et al., 2005), which runs from September 1957 to August 2002. The dataset consists of six-hourly global fields with a $1.5^{\circ} \times 1.5^{\circ}$ grid resolution. ERA-40 was produced using the ECMWF Integrated Forecasting System, a two-way coupled atmosphere-wave model system and a three-dimensional Variational Data Assimilation (3DVAR) scheme. Observations of ocean wind speeds from VOS, buoys, satellite scatterometer and (when available) satellite altimeter SWHs were assimilated in the analysis process.

The ICOADS is a database resulting from the Voluntary Observing Ships' (VOS) scheme (Kent et al., 1993), which is an international program by which ships are recruited by National Meteorological Services for taking and transmitting meteorological observations. The ICOADS database has records of visually observed height, period and direction for wind-waves and swell allowing the evaluation of ocean wave climate (Gulev et al., 2003). However, only $40-60 \%$ of the total number of reports include wave information (Gulev and Hasse, 1998). This type of data has some uncertainties; Guedes Soares (1986a; 1986b) and Gulev et al. (1998) among others have concluded that wave height is always overestimated in VOS observations in comparison with remote sensed data and numerical models in the areas with small SWH. In this work, thanks to the fact that the analysis is specifically conducted along the ship routes and the behaviour of ships and of masters in facing heavy seas is taken into account, a new interpretation of this bias will be given. 


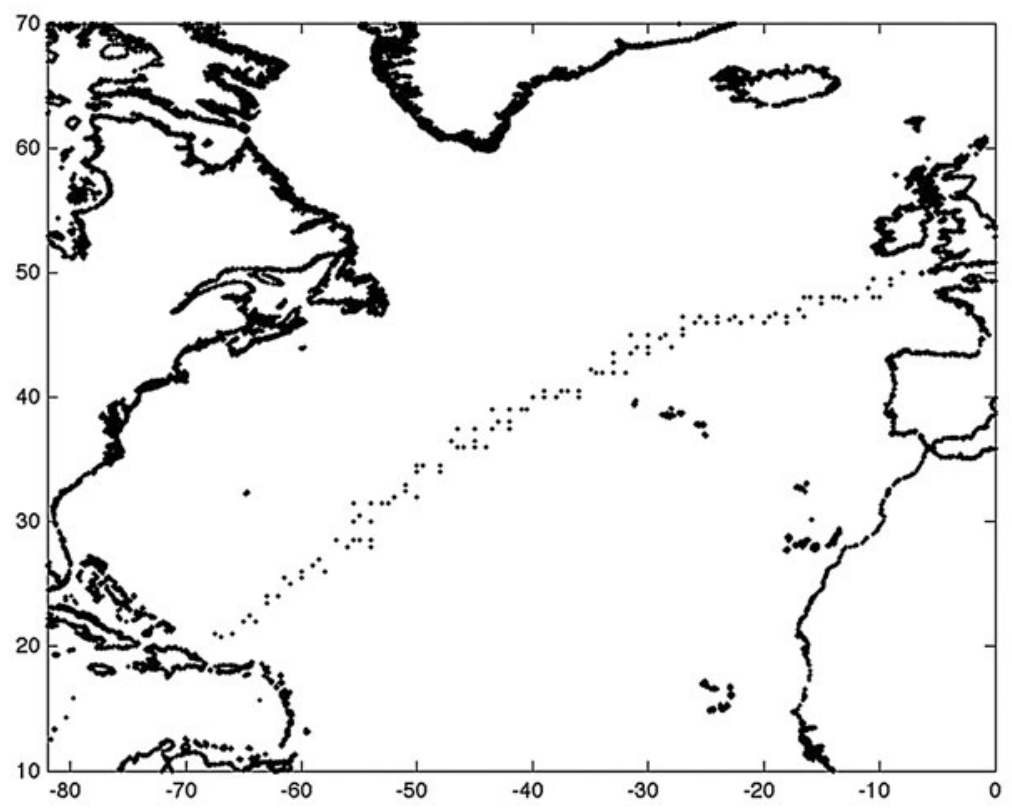

Figure 2. Path and weather data points for Ch_PR-N: Channel - Puerto Rico (north).

VOS data have the irreplaceable value to be the only source of meteorological data along the ship paths and the ones that have the rough weather avoidance built into them. Understanding how this influences the statistics from the VOS database is fundamental.

4. WAVE CLIMATE ALONG THE ROUTES. In order to analyse the wave climate along the routes, it is firstly necessary to select the wave data associated with each route from the databases. The three databases considered are not homogenous in resolution. In particular the VOS data by their nature do not have a resolution, but are unevenly distributed depending on the ships' paths. To bypass this problem, the data are gridded in a squared area of $2^{\circ} \times 2^{\circ}$ around a number of previously defined points (see Vettor and Guedes Soares, 2015).

Figure 2 shows the path and all the coordinates selected from the different databases for the northern route from the Channel to Puerto Rico (Ch_PR-N). Even if the data are not exacly located at the same points, they are close to each other, reflecting the climate of the same area. Thus the derived statistics can be considered consistent.

4.1. Significant Wave Height. A straightforward indication of the severity of the seastate along the routes is given in Figure 3 where the evolution of the average significant wave height by dependency on the longitude are provided for the extreme meteorological seasons: summer (June-July-August) and winter (December-JanuaryFebruary).

ERA40 and HIPOCAS results are comparable both in tendency and amplitude. In the westernmost part of the North Atlantic Ocean (latitudes smaller than $50^{\circ} \mathrm{N}$ ) HIPOCAS tends to heavily underestimate the SWH in winter, especially in the 
Ch_PR-S

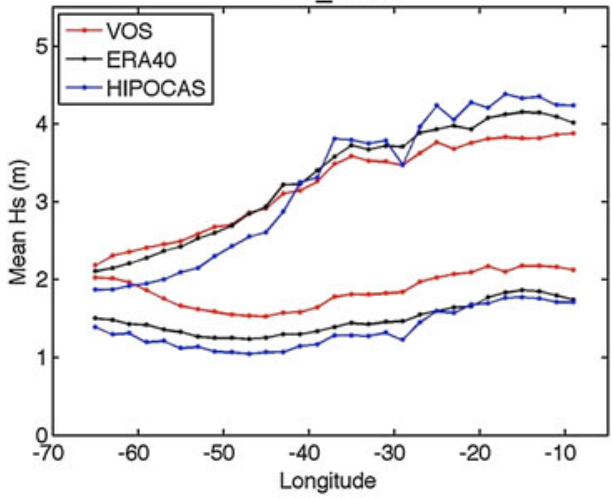

Ch VA

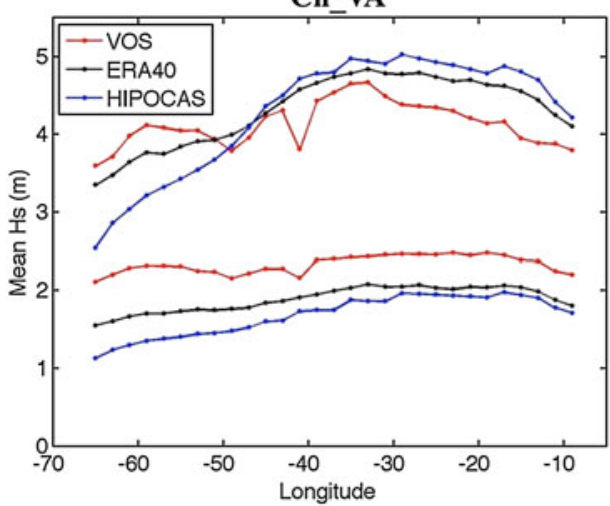

St_VA-N

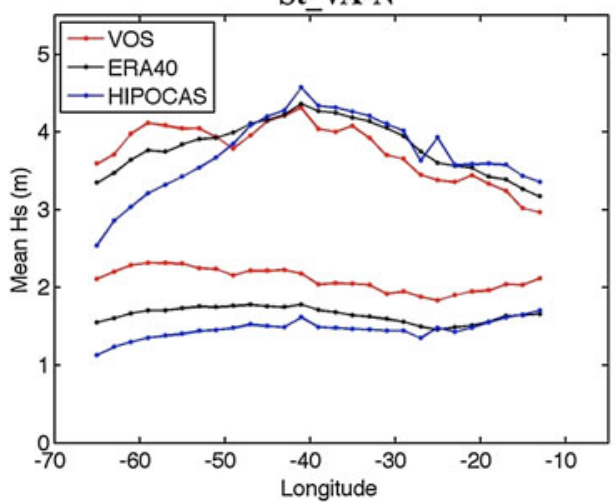

Ch_PR-N

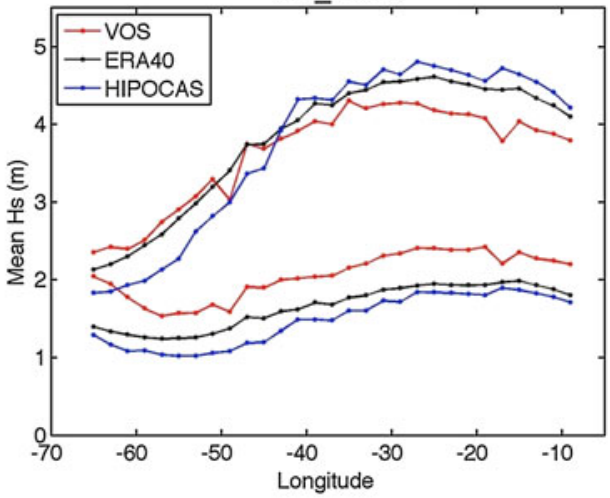

St_MIA

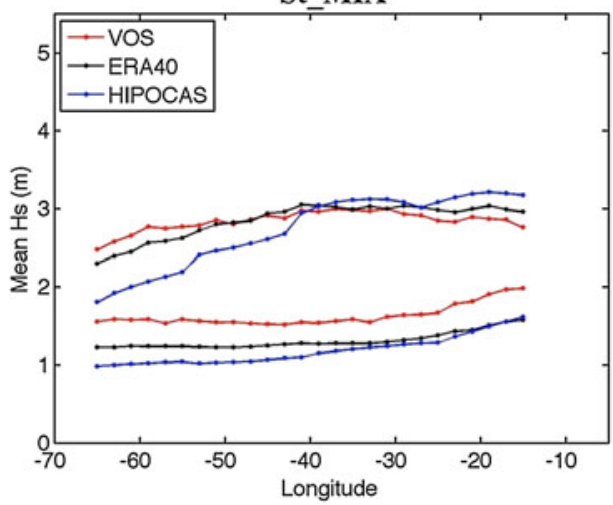

St_VA-S

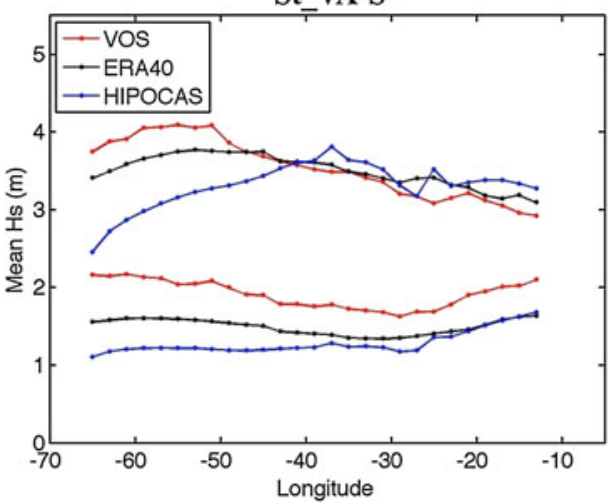

Figure 3. Evolution of the mean SWHs along the North Atlantic routes in winter (higher values) and summer (lower ones) for the three wave databases: HIPOCAS, ERA40 and VOS.

northern part (routes ending in the Virginia area: Ch_VA, St_VA-N and St_VA-S). This can be explained considering the limitations to $64^{\circ} \mathrm{N}$ latitude in the domain used to produce the hindcast database. This might have caused the loss of some information relative to the storms generated closer to the US coasts. VOS averages show a 
strong bias all along the routes in summer and more in general when the $\mathrm{SWH}$ is lower. This issue will be discussed in Section 5 .

Besides the quantitative differences between the databases, some considerations are evident. In winter ships are asked to cross a critical area between $35^{\circ} \mathrm{W}$ and $25^{\circ} \mathrm{W}$ longitude with an average SWH that can reach $5 \mathrm{~m}$, which is in fact near to the North Atlantic SWH climatological maximum, located south-west of Iceland. In contrast, in the area close to the US coast up to $50^{\circ} \mathrm{W}$ longitude, the sea conditions are calmer, around $3.5 \mathrm{~m}$. In summer the weather is more homogeneous and no noteworthy differences were noted in the evolution with a SWH varying between $1.2 \mathrm{~m}$ and $2 \cdot 2 \mathrm{~m}$ depending on the source data.

4.2. Scatter diagrams. While the evolution of the SWH along the route gives a clear qualitative view to estimate how heavy the navigation can be, when ship motion has to be analysed more in detail, the knowledge of the wave periods is essential as it greatly influences the amplitude of ship responses. Moreover, when one is dealing with routes and the life-time ship loads have to be estimated, a long-term study is required. These types of studies are perfomed as an extension of the short term formulations and take into account the occurrences of the various seastates. As an input a scatter diagram has then to be considered.

Traditionally two sources are adopted depending on the scope. When one is verifying the operability of the ship, the global wave statistics database (Hogben, et al., 1986) is the most common reference; it divides the world into large zones allowing consideration of the long term statistics of the areas where the ship will operate. In the design phase a conservative approach is recommended and a standard scatter diagram is adopted (IACS, 2001; Figure 4a), computed considering only the data (modified according to Bitner-Gregersen et al., 1995) of the zones relative to the North Atlantic, which is widely considered as a reference for highly demanding weather conditions.

They are both descriptions of wide areas, which can include zones in which the ship will never operate. If in a design phase it can be accepted both for safety reasons and to allow a possible conversion of the ship, when the operability analysis and schedule management are the goals, more specific input data would improve the quality and reliability of the results. The scatter diagrams proposed here are computed from the ICOADS database only taking into account the data in a narrow belt near the path of the main routes; they are thus more suitable for long-term operational analysis on those specific routes. As a drawback, they need to be re-computed if another route needs to be investigated.

Figure 4 compares the standard scatter diagram with the ones relative to the Ch_VA route, the northernmost and closer to the climatologial maximum, and the St_MIA route, which is the southermost one and shows generally lower waves and higher probability of swell, due to its distance from the area of generation of the extra-tropical storms (Vettor et al., 2014).

4.3. Relative wave heading. Another parameter that has great influence on the ship motions and loads is the relative wave heading (Guedes Soares, 1995). The influence of this parameter is often either neglected considering only the head wave condition (usually, but not always, the most demanding one), or assuming a uniform probability for all the different headings.

In the North Atlantic ocean, waves tend to assume a west-east direction, generally more north-wise above the $40^{\text {th }}$ parallel and south-wise below. On the other hand, the 

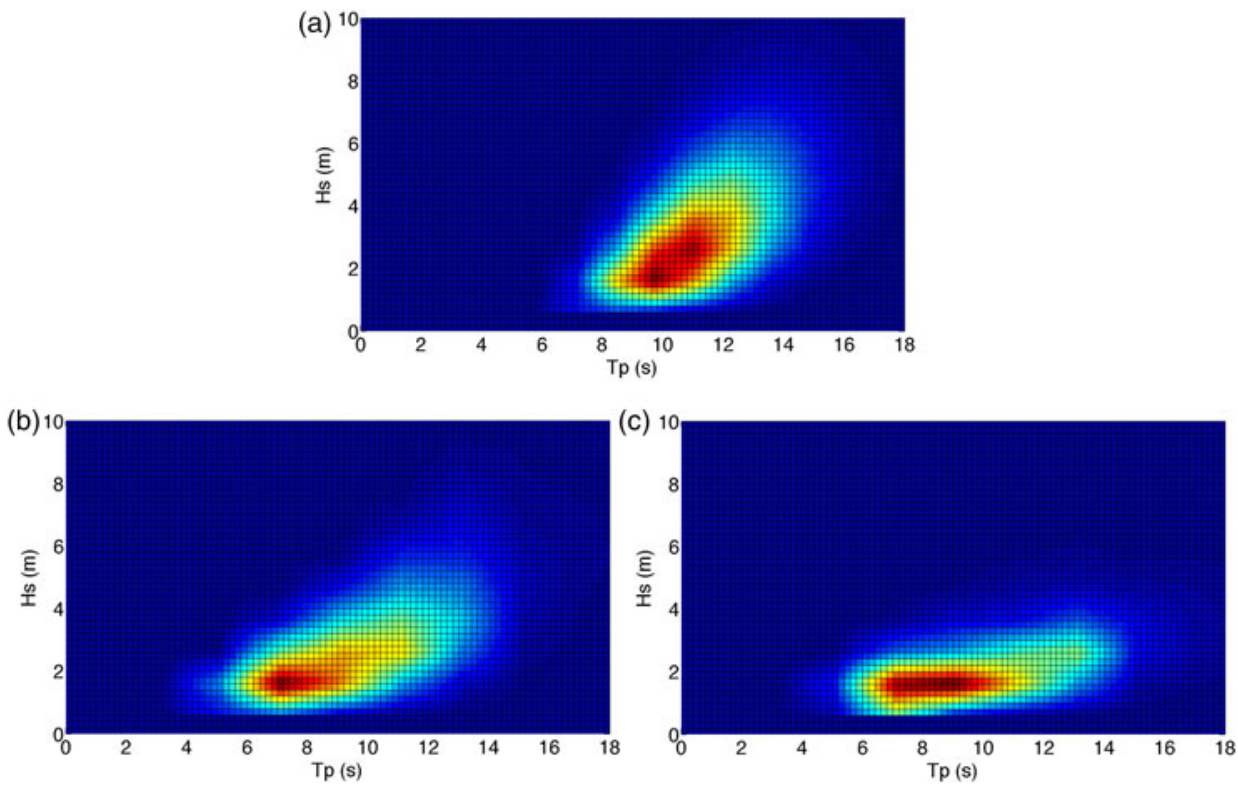

Figure 4. Scatter diagrams for (a) North Atlantic ocean recommended by IACS, (b) route Ch_VA, (c) route St_MIA.

routes can be either eastward when starting from US or westward when starting from Europe. This combination allows assessment of the relative wave heading probability: at each waypoint the main ship course (towards the destination) is compared with the hindcast wave direction (from HIPOCAS database) for the whole period generating an array of relative wave headings from which the histogram is eventually computed.

The relative wave heading probabilities for westward passages for all the routes is shown in Figure 5 (eastward probabilities are obviously symmetrical around $90^{\circ}$ ). In general it can be noted that due to the North Atlantic wave climate and the route direction, ships directed to the Virginia area mostly encounter quartering-head waves (relative heading angle $\theta \geqslant 135^{\circ}$ ).

5. BIAS IN VISUAL OBSERVATIONS. Figure 3 shows a significant bias in the average SWH computed using the VOS database when compared with the ones derived from numerical models. This bias is clearly evident in the summer and generally when the average SWH is low. Figure 6 shows the relationship between the seasonal mean SWH (from ERA40) and the trajectory of the considered routes.

The presence of a seasonal bias in VOS data has been already noted in Vettor and Guedes Soares (2012) where just one point of coordinates $\left(50^{\circ} \mathrm{N}, 23^{\circ} \mathrm{W}\right)$ along the route between the Channel and Virginia (Ch_VA), was analysed. The present study provides evidence that the bias has two main causes: the visual error and the difference due to storm avoidance.

The reliability of the ICOADS database has been discussed in the literature (e.g. Gulev et al., 2003) and studies of the errors in the statistics derived from these data can be found in Guedes Soares (1986a; 1986b) and Gulev et al. (1998) among 

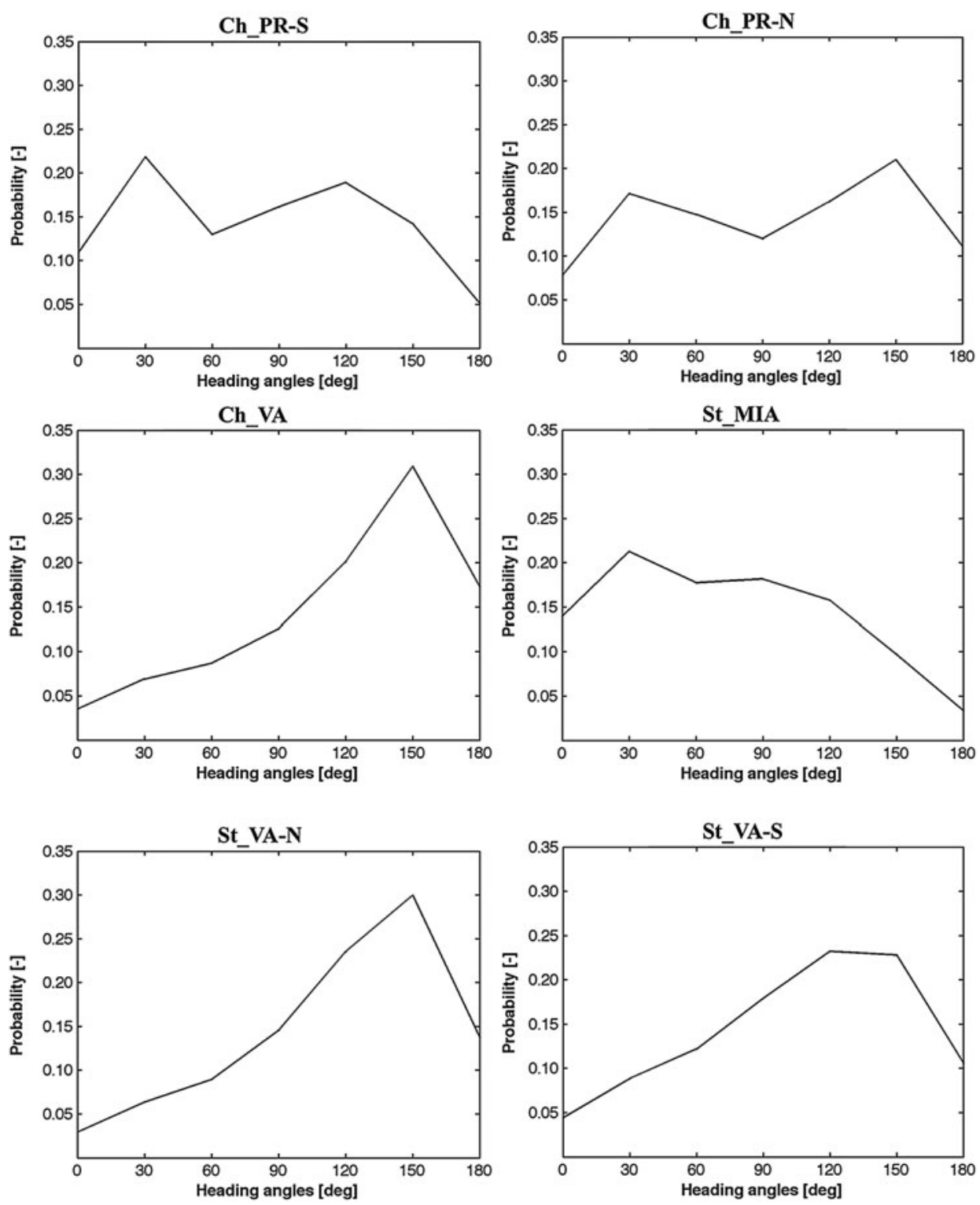

Figure 5. Wave relative heading probabilities in the North Atlantic routes for westward.

others. Generally an overestimation in areas with smaller SWH was identified and some correction has been proposed. The data used in this work have been preprocessed accordingly to correct for those differences (see Vettor and Guedes Soares, 2012). Nevertheless the correction only affects the very small waves (lower than $0.5 \mathrm{~m}$ ) and a bias still persists as can clearly be seen in Figure 3, especially in the summer cases, and requires further investigation.

The solution of the problem would be to understand how this bias works, keeping in mind how the source of the observations can influence the data. A possibility could be 
(a)

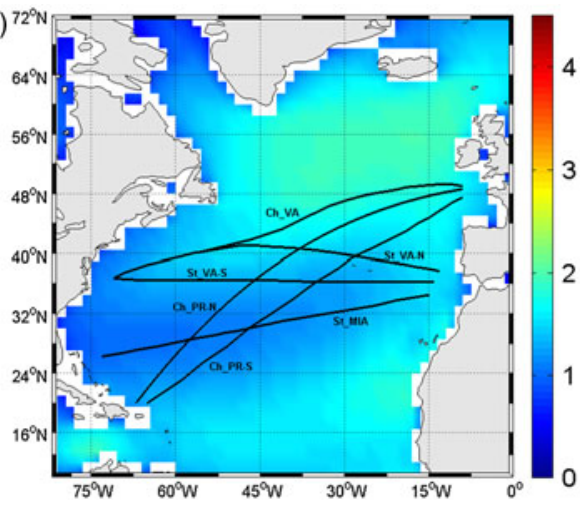

(b)

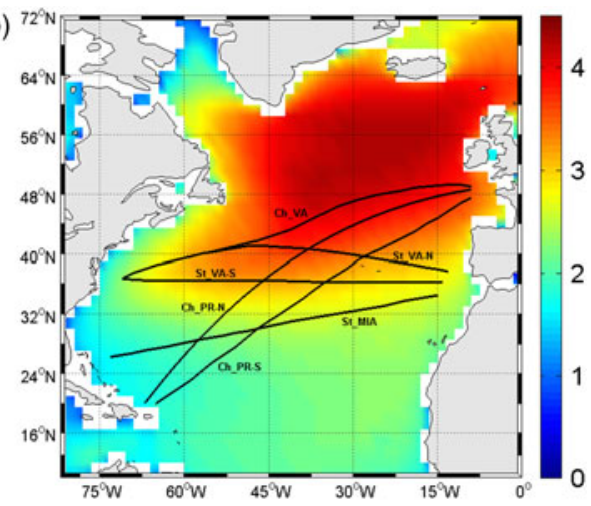

Figure 6. Maps of summer (a) and winter (b) mean significant wave height in the North Atlantic.

to adapt a nonparametric regression method, already applied to wave data (Caires and Sterl, 2005), in order to correct the ICOADS database, using only the more reliable reports. However, since a correction of the database is out of the scope of this paper, a simple method based on logical assumptions will be adopted here.

The main characteristic of the VOS dataset is to be the only source of meteorological data along the ships' paths, which reflects the weather condition in which the ships operate. For this reason, even if the single observation were precise and perfectly reliable, how the masters act when a storm has to be faced would affect the statistics derived from those observations.

In summer and in low SWH situations there is no storm avoidance as there is no storm. This means that statistics can be more significant and reliable, depending on the number of observations, and other factors, but they are not affected by the weather. Instead the differences between the visual results and the numerical databases are due to the visual observation process, which shows as an almost constant value across all longitudes. Determining the average value of this systematic difference allows correction of the data both in summer and in winter, when a separation of visual data and the effect of rough weather would otherwise be hardly possible.

During winter, in addition to the observational bias the storm avoidance bias is also included. After correcting the winter data with the average observational bias determined from the summer, the only bias left is the one related to the rough weather avoidance which can then be determined.

The observational bias computed considering only the summer data is shown in Table 1. It can be seen that it does not significantly differ among different routes, especially when the percentage value is considered. Thus the average percentage value of $20.83 \%$ can be considered representative for all the routes and used to correct the observational component of the bias.

After the correction, the evolution of the mean SWHs along the routes can be seen in Figure 7. Once the observational bias due to errors in observation is corrected, the resulting statistics are assumed to be ruled by the behaviour of ships in waves and the decisions of the masters regarding whether to face or not the forecasted weather conditions. Thus, after this correction, the strong winter bias present in all the routes in the longitude range $\left[50^{\circ} \mathrm{W}, 10^{\circ} \mathrm{W}\right]$ represents the effect of storm avoidance 
Table 1. Bias in the significant wave height in summer (observational bias).

\begin{tabular}{lcccccccr}
\hline & & Ch_PR-S & Ch_PR-N & Ch_VA & St_MIA & St_VA-N & St_VA-S & Average \\
\hline Bias SWH & {$[\mathrm{m}]$} & 0.44 & 0.49 & 0.55 & 0.39 & 0.55 & 0.52 & 0.49 \\
& {$[\%]$} & 20.95 & 21.25 & 20.80 & 18.71 & 21.14 & $22 \cdot 15$ & 20.83 \\
\hline
\end{tabular}

on wave statistics from VOS reports, while during the summer there are no significant differences among all three databases. The reduction of the mean SWH from $0.8 \mathrm{~m}$ for the southernmost routes (St-MIA and St-VA-S) up to $1.3 \mathrm{~m}$ for the northernmost ones (Ch-PR-N and Ch-VA) is shown.

6. STORM AVOIDANCE CORRECTION. Looking at Figure 7, some results are clear. In general the bias increases going from west to east and in some cases this trend seems more regular and almost linear. As can be seen in Figure $6 \mathrm{~b}$ and as the scatters of the bias versus the longitude (not shown here) demonstrated, this behaviour is accidentally due to the fact that the climatological maximum of the SWH in winter is located in the north east part of the North Atlantic basin, thus the increase of the bias with the longitude actually corresponds to the increase in the SWH.

More interesting is to determine how storm avoidance is correlated with the intensity of the weather. In Figure 8 the scattering between the winter storm avoidance correction (mean of numerical minus corrected observed SWH) is shown. In the first four routes the correlation is clear and the bias increases linearly with the SWH. In areas characterised by sea states with an average SWH of $4 \mathrm{~m}$, ships experience conditions with SWH reduced of about $1 \mathrm{~m}$.

In the routes between the Strait of Gibraltar and the north-east side of the USA (St_VA-N and St_VA-S) the scatter is wider, especially in the second/southern one. This is due to the westernmost part of the routes close to the Virginia area (highlighted in the red circles in Figure 8 and also evident in the scatter of the SWH with the longitude, not shown here) where the effect of storm avoidance is low (between 0 and 20 $\mathrm{cm}$ ) even in quite demanding sea-states (between 3.0 to $3.5 \mathrm{~m} \mathrm{SWH}$ ). It can be noticed that even the route between the Channel and the Virginia (Ch_VA) area is affected by this circumstance which contributes to make the slope of the regression higher.

To find an explanation it is necessary to take into account the mean peak periods. In winter, due to the short fetch, the wave climate in the northwest part of the North Atlantic basin presents a local maximum of the wind-sea waves (lower peak periods), whereas the swell waves' amplitude is in line with the global climate of the basin (see Vettor et al., 2014). This means that this area is characterised by local storms, which are more difficult to predict for the master than the global climate and the swell waves, as demonstrated by the high rate of weather related accidents offshore the US Atlantic coast (Guedes Soares et al., 2001), especially for ships sailing westward, which leave the European coast five to seven days before reaching the destination and have to plan the voyage using medium-long term weather forecast.

These considerations suggest also including the wave period in the analysis. The mean SWH, although being an important factor (with a global correlation coefficient equal to $0 \cdot 88$ ), is not fully sufficient to understand the effect of weather routing and storm avoidance on the weather conditions experienced by the ships. The confirmation is given in Figure 9 where the correlation between the storm avoidance correction and 
Ch PR-S

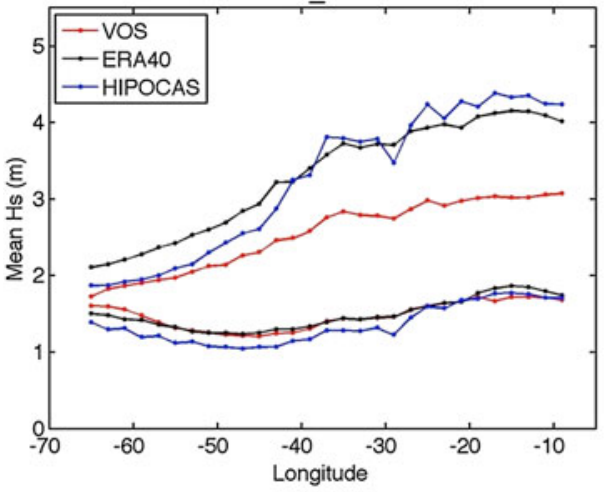

Ch VA

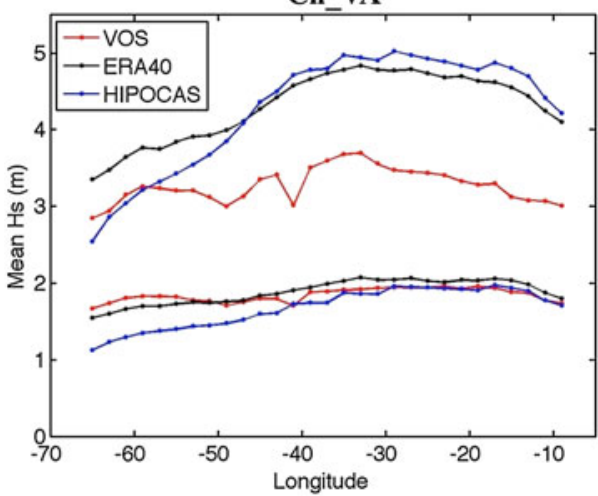

St VA-N

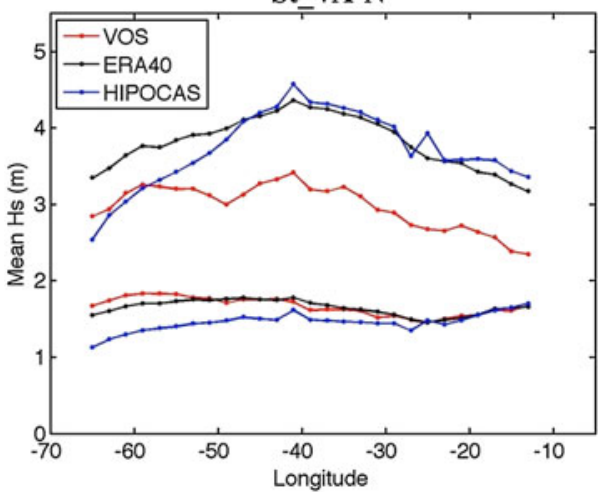

Ch PR-N
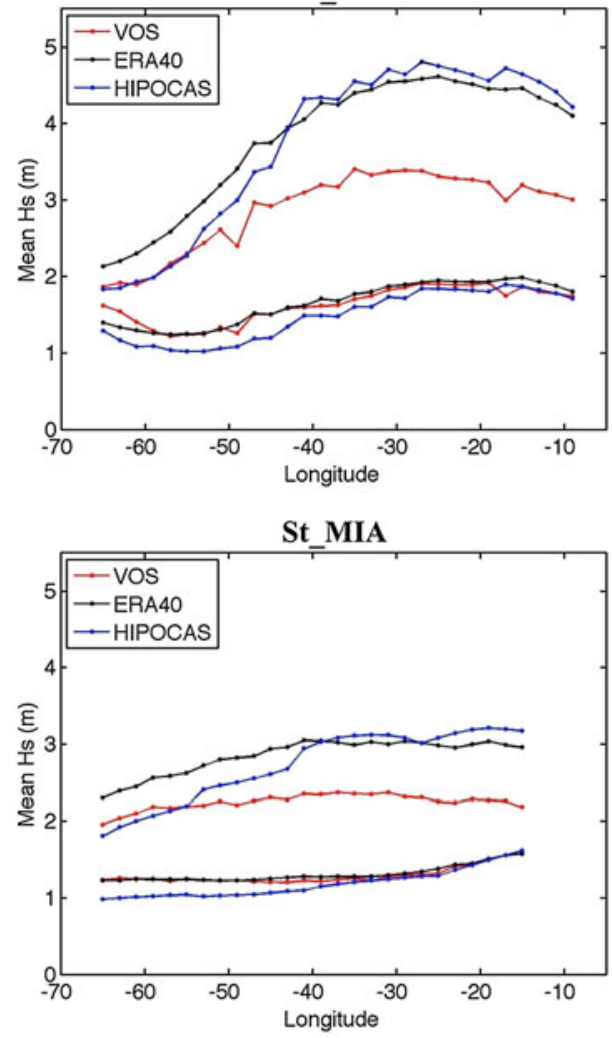

St_VA-S

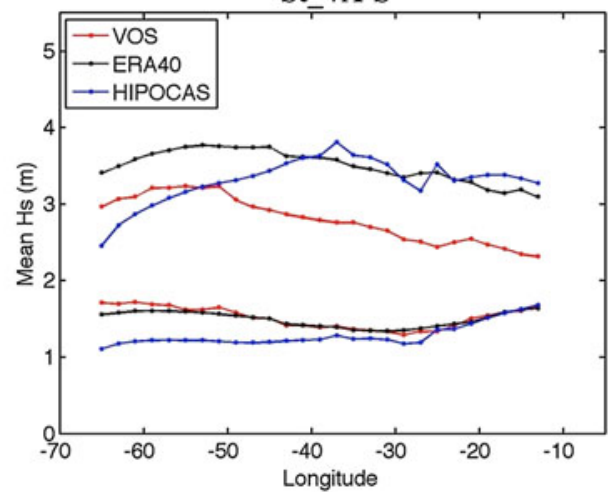

Figure 7. Evolution of the mean SWHs along the North Atlantic routes in winter (higher values) and summer (lower ones) for the three wave databases: HIPOCAS, ERA40 and the corrected VOS.

the mean peak period is shown. The red-circled outliers of Figure 8 do not appear in this case, suggesting that they were indeed caused by the wave steepness (wave height wave period ratio) and how the ships face those conditions. All in all the correlation coefficient between the storm avoidance correction and the peak period is equal to 0.82 . 


\section{Ch_PR_S}
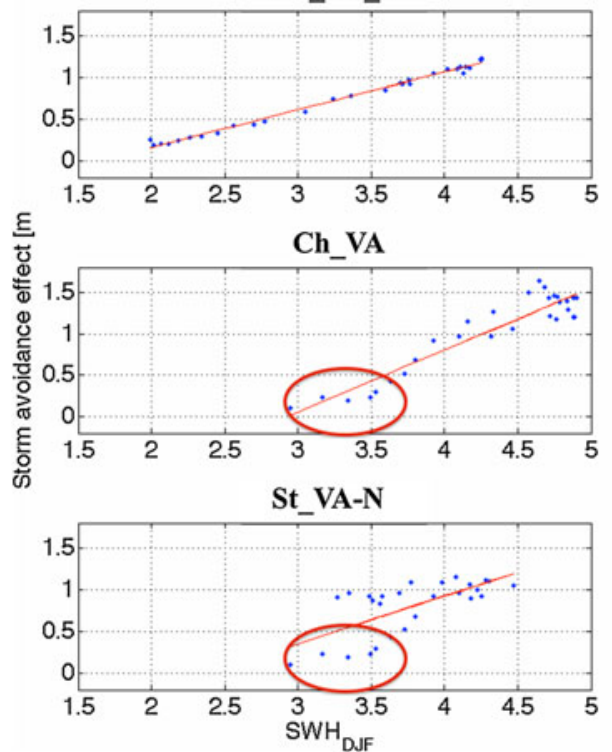

Ch_PR_N
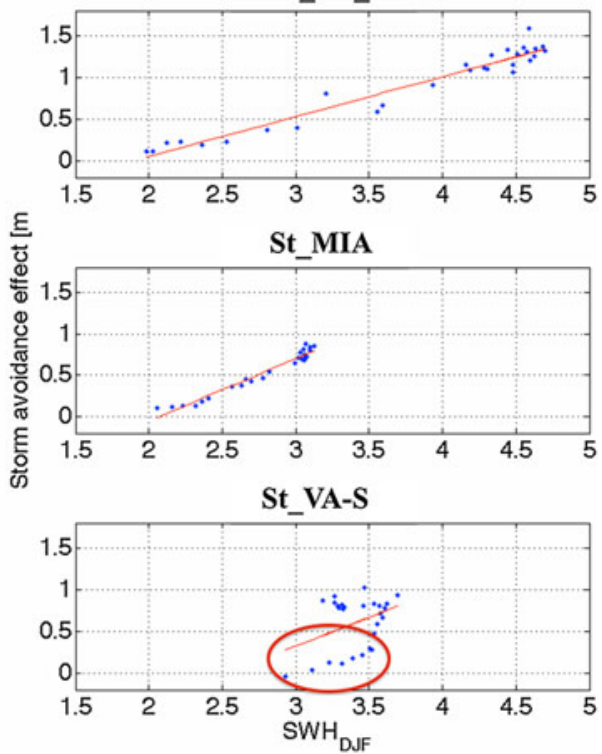

Figure 8. Scatter of the bias due to the winter storm avoidance effect versus the actual winter SWH for each route (data referred to the north-west part of the North Atlantic basin are red-circled) and relative linear regressions.
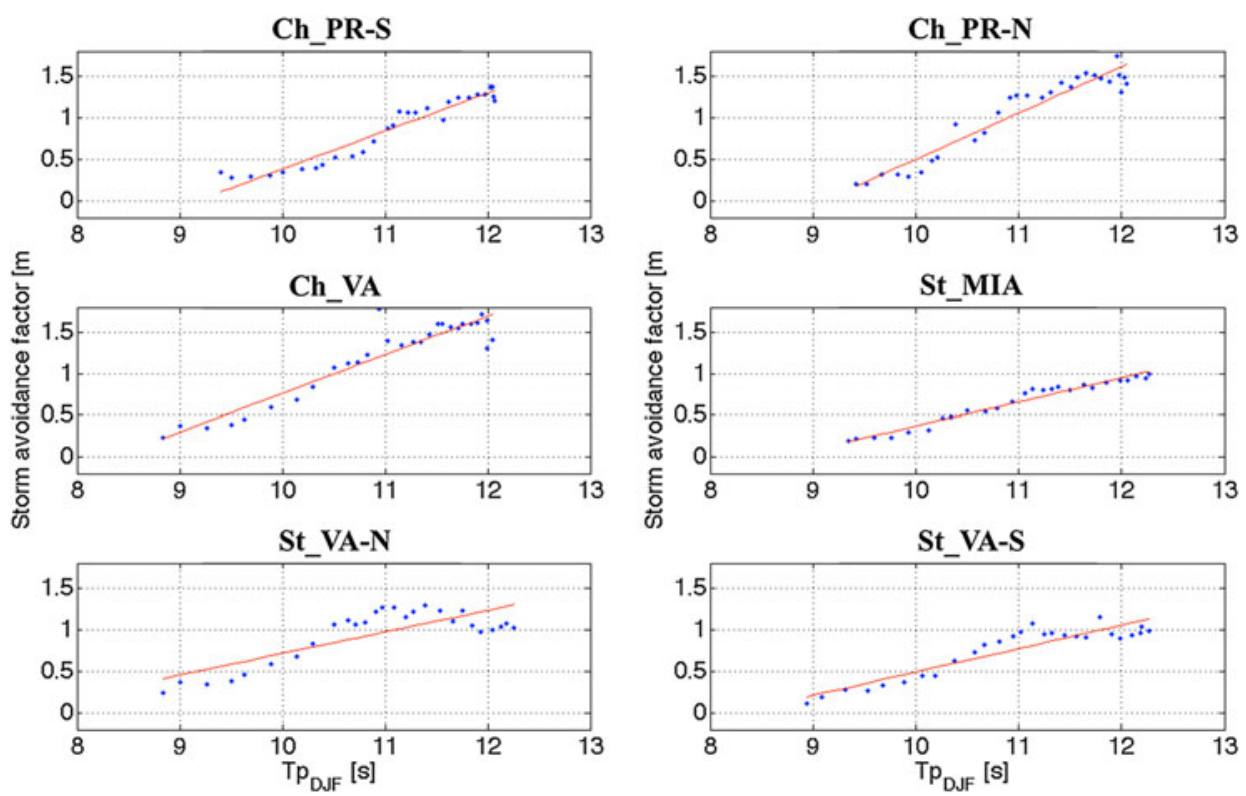

Figure 9. Scatter of the storm avoidance correction versus the actual peak period for each route and relative linear regressions. 

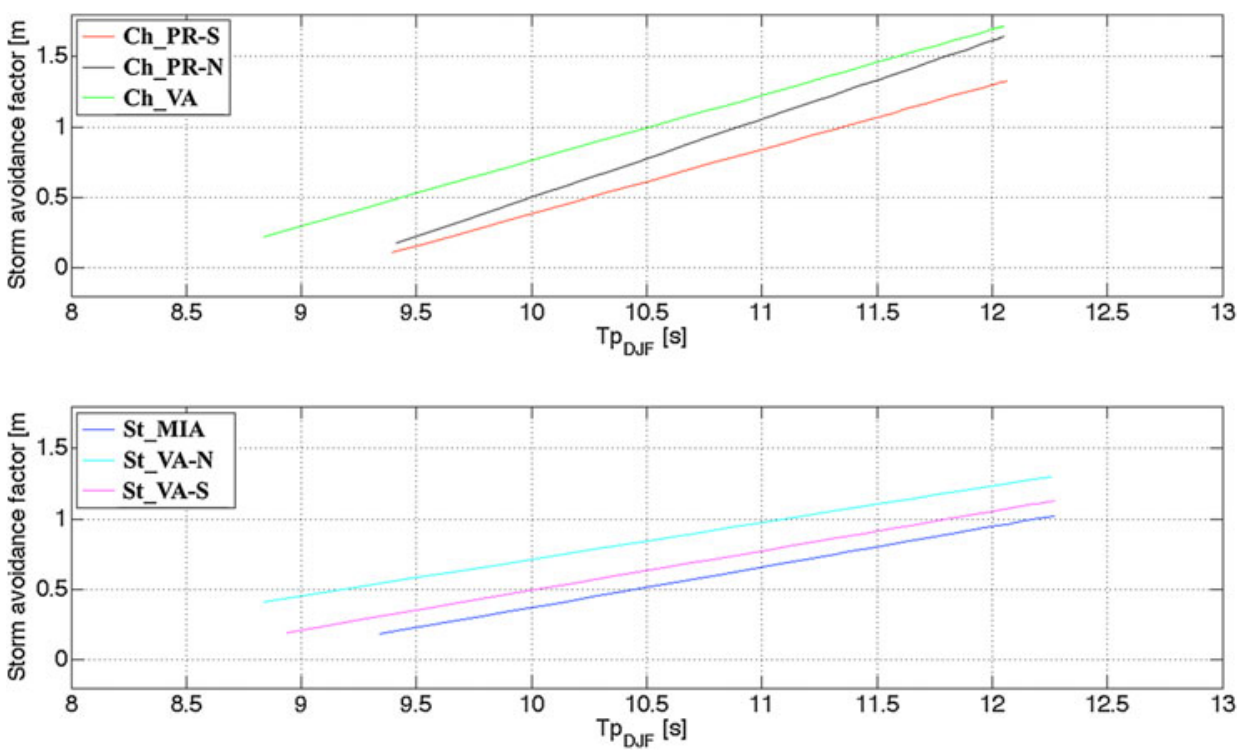

Figure 10. Linear regressions of the storm avoidance correction versus the actual peak period.

The correlation is strong and adequately represented by a linear regression in all cases. Nevertheless, as shown in Figure 10, the gradient as well as the magnitude of the regression differs from one route to the other. The former is similar for the three routes including respectively the Channel and the Strait of Gibraltar, while the latter is step by step higher as the route moves further north.

From the previous considerations it appears fundamental to take into account both parameters as in Figure 11. In this case a bilinear regression (Equation (1)) seems to be suitable and to keep in consideration the two most important variables ruling storm avoidance. As a result one can extend the meaning of the equation considering that, if in a region or along a route the mean wave climate is known in terms of SWH and peak period, thanks to the storm avoidance effect the average SWH that a ship will encounter can be estimated from:

$$
\text { Storm_Avoidance_Correction }_{\text {mean }}=0 \cdot 3446 \cdot S W H_{\text {mean }}+0 \cdot 2183 \cdot T p_{\text {mean }}-2 \cdot 7076
$$

The validity of the equation is limited by the boundaries of the input values [ $2 \mathrm{~m}, 5 \mathrm{~m}$ ] for the SWH and [8 s, $13 \mathrm{~s}$ ] for the peak period. This is fundamental mainly for the peak period since changing the encounter frequencies the ship dynamic dramatically changes, while a certain extrapolation might be reasonable for higher SWHs. Table 2 shows the mean SWH that a ship, which follows the common safety recommendations, can expect to encounter while sailing a route characterised by the seastate described by the given SWHs and peak periods. Of course, being a general approach it does not take into account the characteristics of the vessel, but it can probably be a good term of reference for trans-oceanic ships, especially if operating along the same route for a considerable period, as might often happen to a container-ship. 


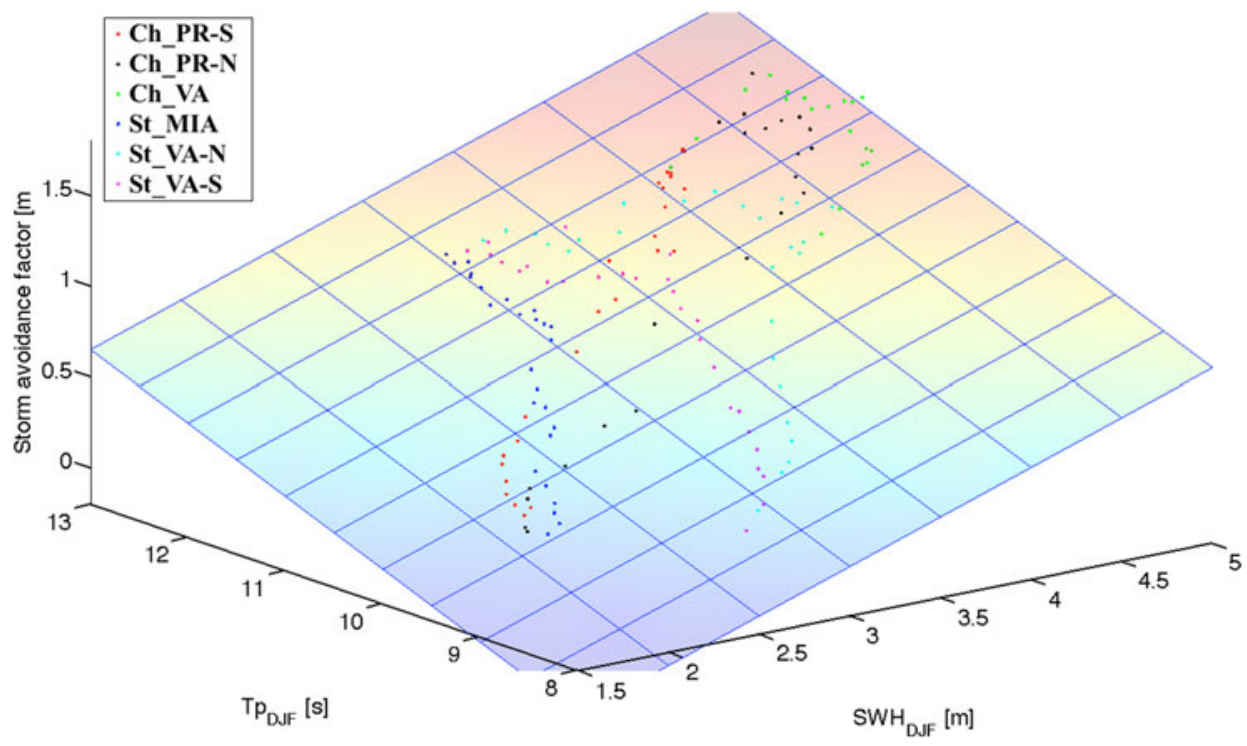

Figure 11. Bi-linear regressions of the storm avoidance correction versus the actual SWH and peak period.

Table 2. Expected mean SWH (in $\mathrm{m}$ ) encountered by a ship sailing a route characterised by a certain sea-state described by means of the SWH and the Tp.

\begin{tabular}{rccllll}
\hline SWH\Tp & 8 & 9 & 10 & 11 & 12 & 13 \\
\hline 2 & - & - & 1,84 & 1,62 & 1,40 & 1,18 \\
3 & 2,93 & 2,71 & 2,49 & 2,27 & 2,05 & 1,84 \\
4 & 3,58 & 3,36 & 3,15 & 2,93 & 2,71 & 2,49 \\
5 & 4,24 & 4,02 & 3,80 & 3,58 & 3,37 & 3,15 \\
6 & 4,89 & 4,68 & 4,46 & 4,24 & 4,02 & 3,80 \\
7 & 5,55 & 5,33 & 5,11 & 4,89 & 4,68 & 4,46 \\
8 & 6,20 & 5,99 & 5,77 & 5,55 & 5,33 & 5,11 \\
9 & 6,86 & 6,64 & 6,42 & 6,20 & 5,99 & 5,77 \\
10 & 7,52 & 7,30 & 7,08 & 6,86 & 6,64 & 6,42 \\
\hline
\end{tabular}

7. CONCLUSIONS. An analysis of the wave climate along the main North Atlantic routes has been presented considering three different sources: two databases generated by numerical wave models (HIPOCAS and ERA40) and weather reports from the voluntary observations. A description of the mean seasonal significant wave height as well as the joint probability of significant wave height and wave period was provided. It showed a mean SWH between $1 \mathrm{~m}$ and $2 \mathrm{~m}$ in summer (lower limit for the southwest portions of the routes and higher limit for the northeast ones) and between $2 \mathrm{~m}$ (approaching to Puerto Rico) and $5 \mathrm{~m}$ (close to the Channel) in winter with a general tendency of increasing from west to east, except for the routes operating in the northwest-southeast direction. Considering its influence in ship response, the relative wave heading was also computed. For the case of westward passages, in the routes directed to the Virginia area ships mostly experience head- 
quartering seas, whereas in the route from the Strait of Gibraltar to Miami/Gulf of Mexico following-quartering sea is predominant.

The evolution of the SWH along the routes highlighted a strong bias on the visual observation in summer and more in general in calmer areas. A calibration of the data taking into account the tendency of ships to avoid heavy weather and its consequences on statistics from the VOS dataset led to a new interpretation of the voluntary meteorological reports, which have been considered to overestimate the SWH by about $20 \%$ of the actual value. This correction allowed the identification of the effect of storm avoidance in the waves that ships experience along a route. The impact of crossing the area of generation of the extra-tropical storms, where the mean SWH is around $4.5 \mathrm{~m}$ in winter, is clear in the routes starting from/directed to the Channel where the mean SWH is up to $1.3 \mathrm{~m}$ less than the one computed by numerical codes.

The concept of storm avoidance correction, indicating the difference between the actual mean SWH and the mean SWH that the ships experience has been introduced. Analysing the correlations between this bias and the commonly used sea-states parameters (SWH and peak period), a general equation to estimate the storm avoidance correction has been proposed.

\section{ACKNOWLEDGEMENTS}

This work was performed within the project SHOPERA - Energy Efficient Safe SHip OPERAtion, which was partially funded by the EU under contract 605221. The first author was supported by the Portuguese Foundation for Science and Technology (FCT - Fundação para a Ciência e Tecnologia, Portugal) under the contract no. SFRH/BD/89476/2012.

\section{REFERENCES}

Bitner-Gregersen, E. and Guedes Soares, C. (2007). Uncertainty of Average Wave Steepness Prediction from Global Wave Databases. Guedes Soares, C. \& Das P. K., (Eds.). Advancements in Marine Structures. London, U.K. Taylor \& Francis Group, pp. 3-10.

Bitner-Gregersen, E.M., Cramer, E.H. and Korbijin, F. (1995). Environmental Description for Long-term Load Response of Ship Structures. ISOPE June 1995, The Hague, The Netherlands.

Caires, S. and Sterl, A. (2005). A new nonparametric method to correct model data: application to significant wave height from the ERA-40 Re-Analysis. Journal of Atmospheric and Oceanic Technology, 22, 443-459.

Campos, R. and Guedes Soares, C. (2012). Comparisons of two wind and wave data sets from the North Atlantic. Maritime Engineering and Technology, Guedes Soares, C. Garbatov Y. Sutulo S. \& Santos T. A., (Eds.). London UK: Taylor \& Francis Group. 473-479.

Chawla, A., Spindler, D.M. and Tolman, H.L. (2012). Validation of a thirty year wave hindcast using the Climate Forecast System Reanalysis winds. Ocean Modelling, 70, 189-206.

Fan, Y., Lin, S. J., Held, I.M., Yu, Z., and Tolman, H.L. (2012). Global Ocean Surface Wave Simulation using a Coupled Atmosphere-Wave Model. Journal of Climate, 25, 6233-6252.

Guedes Soares, C. (1986a). Assessment of the Uncertainty in Visual Observations of Wave Height. Ocean Engineering, 13(1), 37-56.

Guedes Soares, C. (1986b). Calibration of Visual Observations of Wave Period. Ocean Engineering, 13(6), 539-547.

Guedes Soares, C. (1995). Effect of wave directionality on long-term wave-induced load effects in ships. Journal of Ship Research, 39(2), 150-159.

Guedes Soares, C. (2008). Hindcast of Dynamic Processes of the Ocean and Coastal Areas of Europe. Coastal Engineering, 55(11), 825-826.

Guedes Soares, C. and Moan, T. (1991). Model Uncertainty in the Long Term Distribution of Wave Induced Bending Moments for Fatigue Design of Ship Structures. Marine Structures, 4, 295-315. 
Guedes Soares, C. and Trovão, M.F.S. (1991). Influence of wave climate modelling on the long-term prediction of wave induced responses of ship structures. Dynamics of Vehicles and Structures in Waves, Ed. W.G. Price, P. Temarel \& A.J. Keane, Elsevier Science Publishers. 1-10.

Guedes Soares, C. and Trovão, M.F.S. (1992). Sensitivity of ship motion predictions to wave climate descriptions. International Shipbuilding Progress, 39, 418, 135-155.

Guedes Soares, C. and Viana, P.C. (1988). Sensitivity of the response of marine structure to wave climatology. Computer Modelling in Ocean Engineering, 487-492. B.A. Schreffler and O.C. Zienkiewicz Editors, Rotterdam.

Guedes Soares, C., Bitner-Gregersen, E.M. and Antão, P. (2001). Analysis of the Frequency of Ship Accidents under Severe North Atlantic Weather Conditions. Proceedings of the RINA Conference on Design and Operation for Abnormal Conditions II, 6-7 November, 2001, London - United Kingdom, pp. 221-230.

Gulev, S.K. and Hasse, L. (1998). North Atlantic wind waves and wind stress fields from Voluntary Observing Ship data. Journal of Physical Oceanography, 29, 1107-1130.

Gulev, S.K., Cotton, D. and Sterl, A. (1998). Intercomparison of the North Atlantic wave climatology from Voluntary Observing Ships, satellite data and modelling. Physics and Chemistry of the Earth, 23, 5-6, 587592.

Gulev, S.K., Grigorieva, V., Selemenov, K. and Zolina, O. (2003). Evaluation of ocean winds and waves from voluntary observing ship data. Advances in the application of marine climatology, Joint WMO/IOC Technical Commission for Oceanography and Marine Meteorology.

Gulev, S.K., Grigorieva, V., Sterl, A. and Woolf, D. (2003). Assessment of the reliability of wave observations from voluntary observing ships: Insights from the validation of a global wind wave climatology based on voluntary observing ship data. Journal of Geophysical Research: Oceans, 108, 3236-3236.

Hogben, N., Da Cunha, L. F. and Olliver, H. N. (1986). Global Wave Statistics, Brown Union, London.

IACS (2001). Recommendation No. 034 - Standard Wave Data. International Association of Classification Societies, http://www.iacs.org.uk/document/public/Publications/Guidelines_and_recommendations/ Pdf/ REC_34_pdf186.pdf (last access 29.05.2015)

Jacob, D. and Podzun, R. (1997). Sensitivity studies with the regional climate model REMO. Meteorological Atmospheric Physics, 63, 119-129.

Kalnay, E., Kanamitsu, M., Kistler, R., Collins, W., Deaven, D., Gandin, L., Iredell, M., Saha, S., White, G., Woollen, J., Zhu, Y., Chelliah, M., Ebisuzaki, W., Higgins, W., Janowiak, J., Mo, K., Ropelewski, C., Wang, J., Leetmaa, A., Reynolds, R., Jenne, R. and Joseph, D. (1996). The NCEP/NCAR reanalysis project. Bulletin of the American Meteorological Society, 77(3), 437-471.

Kent, E.C., Taylor, P.K., Truscott, B.S. and Hopkins, J.S. (1993). The Accuracy of Voluntary Observing Ships' Meteorological Observations-Results of the VSOP-NA. Journal of Atmospheric and Oceanic Technology, 10, 591-608.

Komen, G.J., Cavaleri, L., Donelan, M., Hasselmann, K., Hasselmann, S., Janssen, P.A.E.M. (1994). Dynamics and Modelling of Ocean Waves. Cambridge University Press.

Lionello, P. and Galati, M.B. (2008). Links of the significant wave height distribution in the Mediterranean sea with the North Hemisphere teleconnection patterns. Advances in Geosciences, 13-18.

Papanikolaou, A., Zaraphonitis, G., Bitner-Gregersen, E., Shigunov, V., El Moctar, O., Guedes Soares, C., Reddy, D.N. and Sprenger, F. (2014). Energy Efficient Safe Ship Operation (SHOPERA). Proc. Conference on the Influence of EEDI on Ship Design; RINA HQ, London, UK.

Pilar, P., Guedes Soares, C. and Carretero, J.C. (2008). 44-year wave hindcast for the North East Atlantic European coast. Coastal Engineering, 55, 861-871.

Prpic-Oršic, J., Vettor, R., Guedes Soares, C. and Faltinsen, O.M. (2015). Influence of ship routes on fuel consumption and CO2 emission, Guedes Soares, C. \& Santos T.A. (Eds.). Maritime Technology and Engineering. London, UK. Taylor \& Francis Group, pp. 857-864.

Queirós, J., Bernardino, M. and Guedes Soares, C. (2012). Influence of wave data bases on the long term prediction of wave induced loads in ships. Maritime Engineering Technology, Guedes Soares, C., Garbatov, Y., Sutulo, S., and Santos, T.A. London, UK. Taylor \& Francis Group. pp. 513-523.

Sterl, A. and Caires, S. (2005). Climatology, variability and extrema of ocean waves: the web-based KNMI/ ERA-40 atlas. International Journal of Climatology, 25, 963-977.

Stopa, J.E., Cheung, K.F., Tolman, H.L. and Chawla, A. (2013). Patterns and cycles in the Climate Forecast System Reanalysis wind and wave data. Ocean Modelling, 70, 207-220.

Uppala, S.M., Kållberg, P.W., Simmons, A.J., Andrae, U., da Costa Bechtold, V., Fiorino, M., Gibson, J.K., Haseler, J., Hernandez, A., Kelly, G.A., Li, X., Onogi, K., Saarinen, S., Sokka, N., Allan, R.P., 
Andersson, E., Arpe, K., Balmaseda, M.A., Beljaars, A.C.M., van de Berg, L., Bidlot, J., Bormann, N., Caires, S., Chevallier, F., Dethof, A., Dragosavac, M., Fisher, M., Fuentes, M., Hagemann, S., Hólm, E., Hoskins, B.J., Isaksen, L., Janssen, P.A.E.M., Jenne, R., McNally, A.P., Mahfouf, J.- F., Morcrette, J.-J., Rayner, N.A., Saunders, R.W., Simon, P., Sterl, A., Trenberth, K.E., Untch, A., Vasiljevic, D., Viterbo, P., and Woollen, J. (2005). The ERA-40 reanalysis. Quarterly Journal of the Royal Meteorological Society, 131, 2961-3012.

Vettor, R. and Guedes Soares, C. (2012). Seasonal bias in the voluntary ship observations of significant wave height in a North Atlantic location. Proceedings of the $17^{\text {th }}$ International Conference on Ship and Shipping Research (NAV2012), Naples, Italy.

Vettor, R. and Guedes Soares, C. (2015). Detection and analysis of the main routes of voluntary observing ships in the North Atlantic. Journal of Navigation, 68, 397-416.

Vettor, R., Semedo, A., Guedes Soares, C., Breivik, O., Sterl, A. and Reistad, M. (2014) Wind sea and Swell Waves in the Northeast Atlantic Ocean. Guedes Soares, C. \& Lopez Pena F., (Eds.). Developments in Maritime Transportation and Exploitation of Sea Resources. Francis \& Taylor Group London, UK; pp. 1029-1036.

von Storch, H., Langenberg, H. and Feser, F. (2000). A spectral nudging technique for dynamical downscaling purposes. Monthly Weather Review. 128(10), 3664-3673.

WAMDI Group: Hasselmann, S., Hasselmann, K., Bauer, E., Janssen, P.A.E.M., Komen, G.J., Bertotti, L., Lionello, P., Guillaume, A., Cardone, V.C., Greenwood, J.A., Reistad, M., Zambresky, L., Ewing, J.A. (1988). The WAM model - a third generation ocean wave prediction model. Journal of Physical Oceanography, 18, 1775-1810.

Weisse, R. and Günther, H. (2007). Wave climate and long-term changes for the Southern North Sea obtained from a high-resolution hindcast 1958-2002. Ocean Dynamics. 57, 161-172.

WISE Group: Cavaleri, L., Alves, J.H.G.M., Ardhuin, F., Babanin, A., Banner, M., Belibassakis, K., Benoit, M., Donelan, M., Groeneweg, J., Herbers, T.H.C. , Hwang, P., Janssen, P.A.E.M., Janssen, T., Lavrenov, I.V., Magne, R., Monbaliu, J., Onorato, M., Polnikov, V., Resio, D., Rogers, W.E., Sheremet, A., McKee Smith, J., Tolman, H.L., van Vledder, G., Wolf, J. and Young, I. (2007). Wave modelling - The state of the art, Progresses in Oceanography, 75(4), 603-674. 